\title{
Improving Production System Performance Using Overall Equipment Effectiveness
}

\author{
Clarence Edwin ${ }^{1}$, Wan Muhammad Noor Sarbani Mat Daud2,. \\ ${ }^{1}$ Faculty of Industrial Management, Universiti Malaysia Pahang, 26300 Pahang, Malaysia. \\ 2Faculty of Mechanical and Automotive Engineering Technology, Universiti Malaysia Pahang, 26600 Pahang, Malaysia.
}

\begin{abstract}
In the competition among organization on the global market, no organization will tolerate losses. Overall Equipment Effectiveness (OEE) overall is a new process in which the efficiency of a system is calculated and complicated manufacturing issues are truly simplified to simple and intuitive knowledge delivery. It thinks about the exceptionally important measures of productivity. An endeavour has been done to measure and analyse existing Overall Equipment Effectiveness (OEE) at company Kirino in hope to reduce unplanned downtime losses on equipment failure and tooling damage to maximize the productivity. The methods used to analyse these various causes were analysis tools and Intelligence Systems. After knowing the causes of various activities that leads to high rates of defects, then recommendations for improvements that could be used by company Kirino were ready to be made using intelligent system as a medium of solution.
\end{abstract}

ARTICLE HISTORY

Received: 30-10-2020

Accepted: 05-01-2021

KEYWORDS

Overall Equipment; Effectiveness; Analysis Tools; Intelligence Systems; Total Productive Maintenance; Fuzzy Inference System

\section{INTRODUCTION}

\section{Background of the study}

At world level, the manufacturing plant will the its production costs and retain the consistency of its goods and output in the present extreme competitive market conditions (Irhirane, Bounit, \& Dakkak, 2017). If the business does not cooperate, the plant could be blamed for enormous problems, for example low profit. It has come to the conclusion that quality management can become a tool for manufacturers to build distinctive competitive advantage and thus produce suitable business outcomes where quality is handled in an interconnected way, where managerial support and customer relationships determine the nature of operations.

The introduction of Total Productive Maintenance (TPM) means eliminating six major losses in industry to boost production equipment performance and enhance reliability. These losses include rework and mistakes, return and start, idle time periods and small stops, failure and change loss. The OEE is a commonly used quantitative metric in the industry (Saha, Syamsunder, \& Chakraborty, 2016). This is used not only as an indicator and driver for tracking and controlling production equipment efficiency but also for the enhancement of processes and performance. Recent research to enhance the OEE estimation by overcoming its limitations has been performed. By offering more precise details, this can deter a wrong decision.

The use of Intelligent Systems (IS) technologies in engineering problems are increasing in popularity in these days. The synthesis of non-conventional and traditional methodologies tends to be the solution to the shortcomings in existing methodologies. Therefore, the ambiguous and unreliable data can be interpreted using these non-conventional methods, and the user experience (system knowledge) can be used. In this analysis the approach suggested is used to lead towards an advancement in OEE estimation utilizing non-conventional Intelligence Systems (IS) methods such as Fuzzy Inference Systems (FIS).

The latest approach suggested should be elaborated and the findings tested to see how the aforesaid IS technology will improve the main measuring instruments for the Total Productive Maintenance. This research seeks to explain all the reasons for the overall efficiency of devices and to use IS methods as a new approach to augment the estimation by improved failure and unreliable results. To this end, here are introduced the OEE FIS Estimate Enhancement Strategies.

This study belongs to research stream and is developing a way to take the uncertainties and fluctuations in production into consideration as easily as possible. Without impairing the research, a fluid and not a mathematical method is adopted to optimize the study, since fuzzy is generally considered to be more logical and more in accordance with both technicians and decision makers' cognitive processes. Additionally, the use of a fuzzy solution eliminates the drawbacks of the OEE process and thus applies it to several industries. 
Implementing these IS methods; the following assistances can be probable:

a) IS approaches will reveal versatility and potential in coping with intuitive consumer awareness.

b) Development on OEE dimension in manufacturing plants with dissimilar availability, performance and quality weight factor can be demonstrated.

c) Amount of work is abridged by generating a suitable user interface and translating info into common input/output language.

\section{Problem Statement}

The main objective of this analysis is to improve the Overall Equipment Effectiveness (OEE) of manufacturing equipment in general. The basic goals are as follows in order to achieve this objective:

(a) To reduce and suggest recommendation on the matter unplanned downtime losses on Overall Equipment Efficiency (OEE) value of machines failure and tooling damage in the factory.

(b) To find out the significant Overall Equipment Effectiveness losses by Why Why Because Logical Analysis (WWBLA) worksheet.

\section{Scope of Study}

The purpose of the study is reduced by carrying out analysis scopes. The first was a systematic review of literature to determine the best form of statistics. In addition, a case study was conducted by company Kirino. On the production area. Due to quality problems such as serious faults and large downtimes of machinery it is picked.

\section{Significance of Study}

The findings of this study will redound to the benefit of the company as Overall Equipment Effectiveness (OEE) plays an significant part in the success of today's production system. The increased demand for enterprise to be as lean as practical and cost-effective demonstrates just how critical OEE, life-changing teaching methods are for organizations. Therefore, organisations implementing the suggested methodology resulting from the results of this analysis will be able to better determine their OEE scores as well as improving their production systems performance.

\section{LITERATURE REVIEW}

\section{Effectiveness, productivity and Efficiency}

Effectiveness, effectiveness, in addition performance are used frequently in OEE calculations, so beginning by describing such concepts is beneficial. Outputs are produced through input transformation in a manufacturing process. Key success criteria for software-intensive product development firms are to achieve and maintain a sustainable competitive advantage through business and technology advancement by continuous improvement in processes effectiveness and productivity (Saha et al., 2016). Steel (input) is shaped and converted into a bent metal component, for example, in a press shop. In this phase, energy and labour could be inputs besides raw material. A process's productivity is defined as the percentage of actual output divided by that process's actual input.

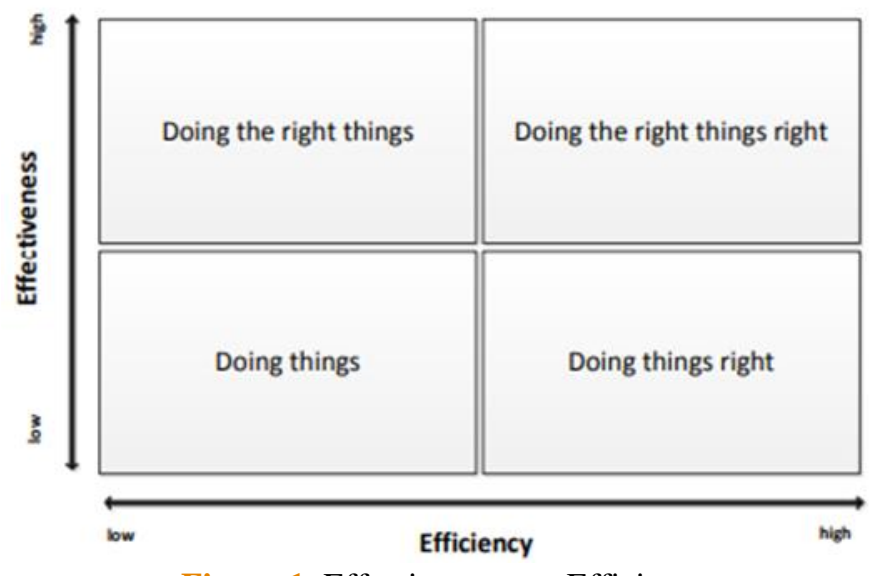

Figure 1. Effectiveness vs. Efficiency

Source: (Singh, Shah, Gohil, \& Shah, 2013) 


\section{Definition of Overall Equipment Effectiveness (OEE)}

Overall Equipment Effectiveness is a main performance metric that can be applied by calculating inefficiencies and sorting them into different categories to measure, assess and enhance a production process. In the manufacturing sector, the improvement of the manufacturing system is one of the intensive improvement efforts undertaken (Ismail, Nurdin, \& Purba, 2018). In other terms, in a manufacturing process OEE is the complete use of time material and facilities.

\section{OEE Factors}

OEE identifies losses and measures significant manufacturing aspects, namely availability, quality and performance (Brandon-Jones, 2014). It helps improve the efficiency and productivity of the machinery. The estimate of three parameters is the OEE of the equipment:

a. Availability:

It is the relation of the time a machine works divided by the time the machines that are available (Brandon-Jones, 2014).

\section{b. Performance:}

A machine's output is the ratio of that machine's total number of parts to its manufacture rate. Efficiency, in simple arguments, calculates the combination of the equipment's actual operating speed and the optimal speed. Please note that a machine's ideal cycle time is the shortest period that can be accomplished under optimal conditions. It is also considered the time of the production process(Brandon-Jones, 2014).

c. Quality:

The quality section of OEE is specified in order to increase insight into the quality component of a manufacture process. The output variable measures reasonable (acceptable) units produced by the machine separated over the production time by the total units generated by the machine.

\section{Losses in industry}

OEE's main objective is to mitigate and/or eradicate the sources of inefficiency in a production process. Damages are usually considered to be a basic knowledge to address OEE. Next is clarified different categorizations of damages.

\section{Planned vs. Unplanned downtime losses}

In 1993, a writer, Ericsson and Dahlén split downtime into two categories, scheduled to stop and unplanned to stop. OEE is concerned, as stated, with inefficiencies within the scheduled production time. Though "expected downtime losses" in a manufacturing environment are called inefficiencies, such losses do not impact the OEE (Tabikh, 2014). They should categorize the following events as expected stoppage:

- Approved pauses

- Not occupied days/weekends

- Trainings/meetings during occupied hours

- Arranged downtime for product changes

- Preventive maintenance/overall

- Equipment adjustment

The following Figure 2 demonstrates unplanned downtime delays in a period of production:

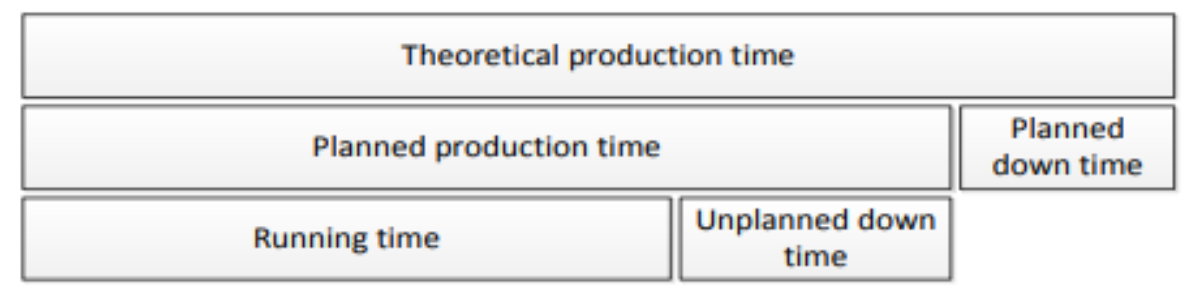

Figure 2. Planned/Unplanned downtime Source: (Tabikh, 2014)

\section{Six Big Losses}

The so-called "six major losses" are the most common reasons of inefficiency in the produce, which can be divided into downtimes failure, loss of speed and quality. To order to find a way to monitor and improve production processes (Rahman, Hoque, \& Uddin, 2014), six large losses are addressed as follows. 


\section{i) Downtime losses}

If described earlier, downtime is classified when programmed and unplanned downtime, and unplanned downtime removal is key to OEE improvement. However, downtime is the main factor in increasing plant performance because it is not possible to solve certain problems when the production process is down. Accidents including machine errors, accidental fixes, system failures include incidents involving downtimes (Rahman et al., 2014).

\section{ii) Setup and Adjustment}

Setup and modification losses arise when the manufacture of one product adapts for the manufacture of equipment (Rahman et al., 2014). This is often a series of modifications to machines and/or equipment to provide a product which meets the standards. To order to reduce this loss, the setup time should be monitored. Some systems in industry are used to minimize this loss, such as a single minute die exchange (SMED). Setup and adjustment losses during manufacturing processes can represent warming up times and changes.

\section{iii) Small Stops}

Such pauses arise when the system stops because of a momentary problem such as a trigger that slows down the machine automatically. Such brief pauses are typically fewer than 10 minutes and the dispatcher will cope with them and a repair department is generally not necessary to request them. In most automated lines these losses constitute 20-30 percent of OEE.

\section{iv) Reduced Speed}

Expressive a machine's ideal cycle time and relating it to the actual cycle time, low running or reduced speed losses can be monitored. For various reasons, computers may operate at speeds below the optimum run rate. Operators ' training level, damaged equipment can be categorized as the reasons given above.

\section{v) Start-up Rejects}

Start-up losses occur during a machine's initial start-up until its product quality is stabilized. The investigation of the root cause can be undertaken to determine the possible causes of failure and to avoid similar future losses. It should be remembered that in the production processes, reworks, fragments and wrong configuration are all known as rejections.

\section{vi) Production Rejects}

In a steady-state output, this consistency loss occurs and is not due to start-up. Frequently a six-sigma system with the goal of achieving zero defects is used to decrease the loses of rejected output while concentrating on finding and eliminating reasons of rejection. Damage and restructuring are some examples of non-development losses(Shirose, 1992).

\section{Total Productive Maintenance (TPM)}

TPM is a science and organizational method in which each employee at the company level is worried with their equipment's safety, durability, and performance. Most research involving the OEE measure is therefore linked to repair, but also to areas such as measuring performance and increasing profitability (Humiras Hardi Purba, 2018). Communication is very necessary between managers, maintenance staff and engineers. Engagement and encouragement from top management are one of the key factors fostering staff morale and inspiration.

Training programs frequently improve the manufacturing and repair personnel's expertise and technical capabilities. TPM's objectives are to reduce the entire life cost of equipment \& big six damages and improve OEE. It is a revolutionary repair strategy that has been used to maximize the efficiency of facilities, reduce breakdowns and enhance automated maintenance. TPM's goal is to maintain a minimum of unplanned maintenance. Total Productive Maintenance (TPM) is a maintenance system that incorporates a recently developed plant and machinery maintenance term. The goal of the TPM program is to markedly in ease production while, at the same time, increasing employee morale and job satisfaction (Shirose, 1992).

The objectives of TPM are:

a) Attain zero defects, zero breakdown and zero accidents in all the organization's functional areas.

b) Involve people at all corporate stages.

c) Build various defect reduction and self-maintenance teams.

\section{Intelligent System (IS)}

Intelligent Systems incorporates information, methods, and methodologies to deal with complex real-world issues. Use specific IS methods like Fuzzy Logic in a variety of issues is beneficial. Some of these IS methods are quickly discussed below, such as Fuzzy Inference Systems: 
The Fuzzy Inference System has three elements: a fuzzifier which translates the input into language terms with the membership function, an inference motor that uses rules that can convert fluid inputs to outputs, and a defuzzifier which extracts the fuzzy inference motor performance to narrow outputs that most match the Fuzzy set. The Fuzzy Systems are particularly oriented and active on modern information processing, industrial management, decision-making, pattern recognition, diagnostic research, etc. (Saha et al., 2016). "The Fuzzy Inferior Device uses smooth inputs and outputs to add a nonlinear projection from its input space to its output space."

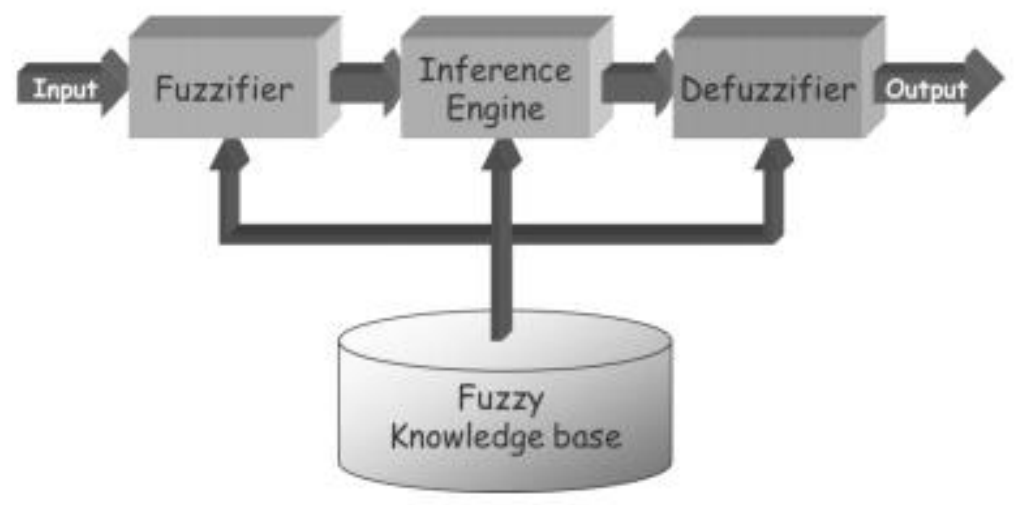

Figure 3. A Fuzzy Inference System.

Source: Carboni, A. (Carboni, Ragaini, \& Ferrero, 2017)

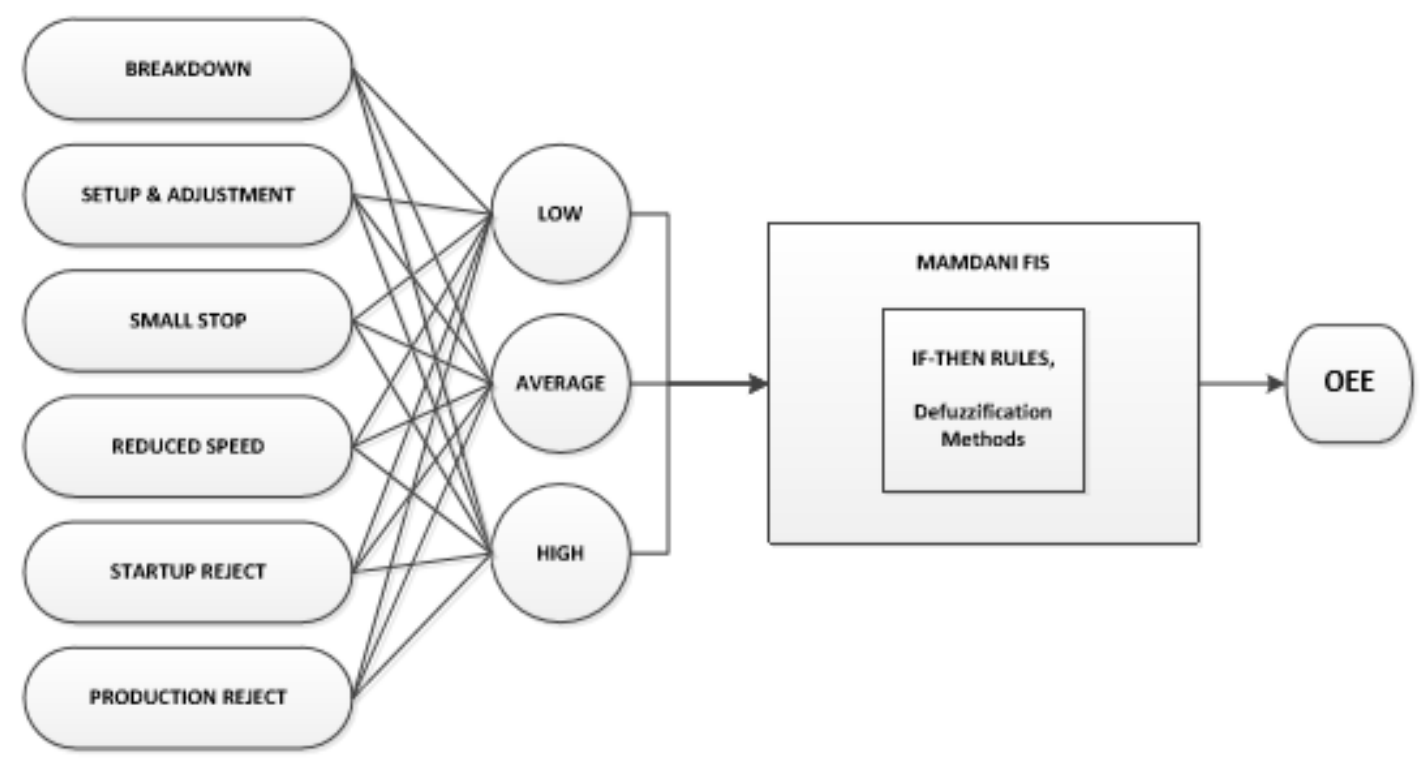

Figure 4. A Mamdani Fuzzy Inference System.

Source: (Pourjavad \& Mayorga, 2019)

Why Why Because Logical Analysis (WWBLA) worksheet is a probing approach that contributes to the discovery of a problem's underlying cause(s). What is the intention of an examination of why-why? A why-why is conducted to find approaches to a problem that solves the root cause(s) of it. 


\section{THE CASE COMPANY}

\section{Company Background}

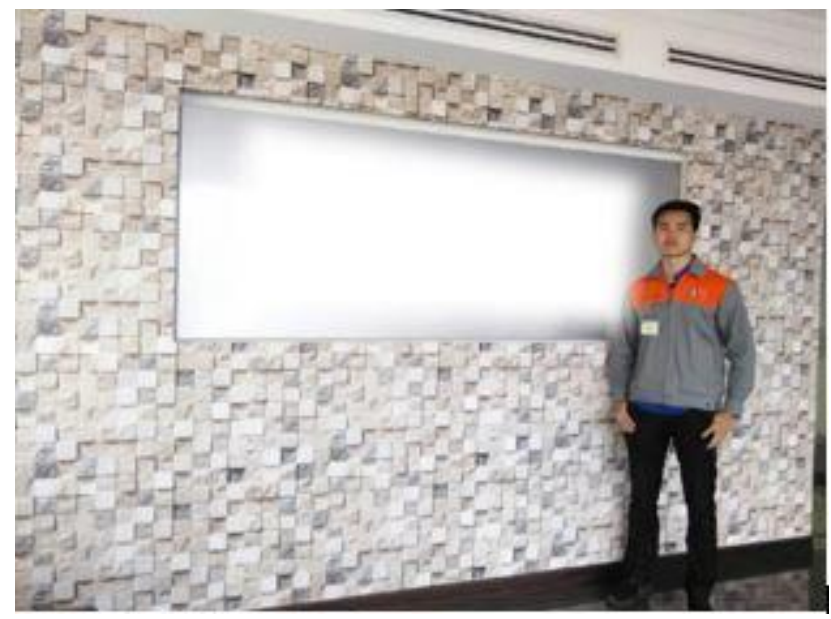

Figure 5. company Kirino Lobby Area

After 1976, company Kirino is headquartered in Jalan Tanjung Api, Kuantan, Pahang. company Kirino is a division of Jovlis Plc, a publicly listed company listed on the stock exchange of London FT. In the year 2000, Jovlis Plc acquired company Kirino. Jovlis Plc offers a wide range of magnetic devices and solutions for aircraft, automobile, manufacturing and medical applications. company Kirino brand specializes in power transformers, inductors and chokes, offering a wide range of accreditations to both unique and regular items. Jovlis Plc now have around 4000 employees globally and around 600 employees work in company Kirino.

\section{Company Problem}

Referring to 1.2 Problem Statement statements, we consider that the overall equipment performance (OEE) of company Kirino was poor. This increase in the overall effectiveness of equipment (OEE) was for the company's continuous improvement. But when measuring the OEE value, this influences the supply, efficiency and consistency.

\section{How does the Company Handle the Problem}

Operators and administrators frequently disagree with each other after company Kirino conduct some study research and are not able to work hand in hand. In many instances, this is troublesome, as both operate in their own ways and do not follow the same rules and priorities. Some disputes result from this circumstance and can bring an organisation in total chaos at times. In order to improve operators ' willingness to work and to improve the global work produced on a shop floor, it seems important to explore this area. To address this, the organization frequently performs a variety of case studies on the condition that company Kirino performed internally. Bad communication can lead to disaster situations in any organization. Most companies feel their internal communication is good enough to run the company. It's often right to stay at an acceptable level, but not enough to improve an organization and change it. It is important to consider and comment on how to manage connectivity and systemic transition in the case of OEE implementation.

\section{METHODOLOGY}

This chapter outlines new measurement methodologies of the OEE based on the techniques proposed by intelligence systems. The emerging approaches of Intelligence Systems (IS) have several benefits over conventional OEE estimation processes. Some of the recompenses of applying these OEE measurement IS strategies are listed below:

- $\quad$ For first, it is necessary, independently of the production process, to calculate all manufacturing plants in various industries.

- $\quad$ The OEE variables used in weighing based upon the method may be given different weight factors. Performance might play a more vital role in calculating equipment performance, for example, in the aerospace or medical equipment industry instead of in equipment availability; higher weight can therefore be assigned to OEE qualitative variables.

Also used was an analytical tool to boost the organization's OEE, which was the research sheet Why Because Logical Analysis (WWBLA). 


\section{Approach with Fuzzy Inference Systems (FIS)}

As already indicated, Fuzzy Logic is the subject of certain of the latest methodologies suggested for OEE assessment. Usually, the Octave uses a computer language and/or interface to represent a number of situations and understand countless inputs and outputs. It is important to remember that while in this work Octave and its Fuzzy Toolbox are used as computer language, the proposed Fuzzy Inference Model can be implemented on another programming platform / framework such as Matlab. In order to achieve optimal results, we suggest the following steps to explain the mechanism of Fuzzy Inference Systems:

a) Objective Definition: It is possible to define specific goals to be met after the process is completed.

b) Observation of the environment: the weight factor of each parameter and the collection of suitable membership functions are classified in this stage by evaluating the mechanism and considering all inputs and outputs. For example, by analysing the atmosphere of the OEE calculation by means of FIS, output losses can be considered with increased weight or time consumption, as another input can be achieved.

c) Set rules: If-then rules are set by a device professional; they will describe the connection between inputs and outputs in the real-life system. It is a potential cause of incorrect outcomes to set rules that do not match the system.

d) Proper FIS selection: various Fuzzy Inference Systems, such as Mamdani, are used to represent a system that is based on processes and goals more precisely.

e) Action: once a Fuzzy Inference Systems model with inputs, outputs and control tests have been developed, targets can be identified.

\section{Approach with Why Why Because Logical Analysis}

It is possible to identify the root causes of the problem using the WWBLA. That major issue is considered separately in this methodology and a worksheet is created. A trigger is known for a major problem and the first element is named for a question. It is then checked that it can be separated into different root causes. Then the second element is defined and tested for the question. It recognizes a third factor of the issue. If further detection is not necessary, the check will be identified. Eventually, countermeasures for the root cause of the problem are found.

\section{RESULT AND SUGGESTIONS}

This chapter presents the effects of the proposed implementation of the Intelligent System (IS) techniques outlined in Chapter 4. Based on different conditions, the outcomes of each approach are examined.

First, the OEE is calculated using a Fuzzy Inference System (FIS) version of Mamdani and the findings are evaluated to check this method's accuracy. The results obtained are evaluated and contrasted in order to demonstrate the consistency of the methodologies described above. The following is listed in Chapter 5:

a) Execution of proposed methodologies in Chapter 4 and procurement of practical results.

b) Analysing obtained results from diverse scenarios. 
Table 1. Why Why Analysis Table

\begin{tabular}{|c|c|c|c|c|c|c|}
\hline Why 1 & Why 2 & Why 3 & Why 4 & Why 5 & Why 6 & Root Cause \\
\hline $\begin{array}{l}\text { Low } \\
\text { OEE } \\
\text { Score }\end{array}$ & $\begin{array}{l}\text { Collecting } \\
\text { to much } \\
\text { data }\end{array}$ & $\begin{array}{l}\text { Low } \\
\text { thresholds of } \\
\text { downtime }\end{array}$ & $\begin{array}{l}\text { Frequent } \\
\text { machine } \\
\text { breakdown }\end{array}$ & $\begin{array}{l}\text { More running } \\
\text { time of } \\
\text { Machine }\end{array}$ & $\begin{array}{l}\text { Poor } \\
\text { productivity }\end{array}$ & High rate of reject \\
\hline & & $\begin{array}{l}\text { Focusing on } \\
\text { OEE Score - } \\
\text { not } \\
\text { underlying } \\
\text { loses }\end{array}$ & $\begin{array}{l}\text { Excluding } \\
\text { Changeovers }\end{array}$ & $\begin{array}{l}\text { Using } \\
\text { 'budget' or } \\
\text { 'standard' } \\
\text { speeds for } \\
\text { Ideal Cycle } \\
\text { Time }\end{array}$ & $\begin{array}{l}\text { Untally data for } \\
\text { OEE Score } \\
\text { measurement }\end{array}$ & $\begin{array}{l}\text { Poor } \\
\text { implementation of } \\
\text { OEE }\end{array}$ \\
\hline
\end{tabular}

From the Table 1, the company root cause can be identified as:

- High rate of reject in production

- Poor implementation of OEE measurement.

\subsection{Fuzzy Inference Models}

The Octave Program has been used to incorporate the Mamdani and Sugeno FIS proposed under Chapter 4. As previously noted, the FIS has six significant losses as industry inputs and OEE is its only production. In this case, while inputs and output of this procedure are the same as previously mentioned with Mamdani FIS, the Sugena FIS can in this case be used in processes where inputs can be given to a weight factor. Effectiveness of this method is based on inputs based to the input value of inputs, the inputs of the FIS are calculated according to the law. In other terms, the input output to the device can be equated. To order to avoid confusion, we consider a simple production line of three computers. Please note that with different numbers of machines and more complex production lines, the same methodology can be used for different processes.

\subsection{OEE Measurement Experimental Results}

As mentioned above, various scenarios are presented for each approach. The industrial conditions will then be taken into account and the program will receive input values and the OEE will be obtained. The situations discussed are often evaluated to show the consistency of the methodologies. A brief account of each situation is provided in this chapter along with a list of inputs and tests. Remember that such approaches can be used in order to achieve the same output for different production processes, regardless of production process and input variances.

\section{OEE Measurement Using Mamdani FIS (Intelligent System 1)}

\section{Scenario\#1}

A machine was selected and its OEE shall be measured in a manufacturing facility. Assuming that this machine has been linked to qualitative losses during the past month, however, its performance is average and during the same period the machine was also available for operation. The following assumptions are therefore taken into consideration: 
- Although in this period a small breakdown occurred; the system was running continuously and its operator finds the importance of the lack of breakdown to be minimal. The losses associated with the system were not set-up and modification and these losses are considered low.

- Small stops occurred during runtime within the last month and were fixed by the operator so that the loss of small stops for this machine is considered average.

- The optimal cycle time of machines for pressing the metal part is 12 seconds but its real cycle period is estimated as 15 seconds and decreased speed loss by operator has been deemed normal.

- There was no significant amount of start-up rejections, and this failure in this time was considered low.

- Qualitative issues were identified and this system created notable amount of non-conforming parts within last month. Therefore, this time is known to be strong in the cycle of denying the loss.

- The supply metrics have a higher weight factor than efficiency and cost in this production site, because of their short cycle time and low price. In turn, the system improves its working time and reduces set-up and set-up times by applying the Full Productive Maintenance (TPM) and Single Minute Die Echange (SMED).

The following Table 2 presents the results as inputs of Mamdani FIS to amount OEE considering the above parameters:

Table 2. Calculation Output Based on Mamdani FIS

\begin{tabular}{|c|c|c|c|c|c|}
\hline $\begin{array}{c}\text { Input } \\
\text { parameters }\end{array}$ & $\begin{array}{l}\text { Linguistic } \\
\text { term }\end{array}$ & $\begin{array}{l}\text { Input } \\
\text { value }\end{array}$ & $\begin{array}{r}\text { Output } \\
\text { parameters }\end{array}$ & $\begin{array}{c}\text { Output } \\
\text { linguistic term }\end{array}$ & $\begin{array}{l}\text { Deffuzzified } \\
\text { output value }\end{array}$ \\
\hline Breakdowns & High & $24 \mathrm{~h}$ & OEE & High & $75.2 \%$ \\
\hline $\begin{array}{l}\text { Setup and } \\
\text { adjustments }\end{array}$ & High & $1.9 \mathrm{~h}$ & & & \\
\hline Small stops & Average & $42 \mathrm{~h}$ & & & \\
\hline Reduced speed & Low & $1 \mathrm{~h}$ & & & \\
\hline Start-up rejects & Average & $\begin{array}{l}124795 \\
\text { pieces }\end{array}$ & & & \\
\hline Process rejects & High & $\begin{array}{l}14975 \\
\text { pieces }\end{array}$ & & & \\
\hline
\end{tabular}

Because of the above values as inputs and weight variables, the resulting OEE was obtained as 75.2 percent, as can be seen from the graph. Remember that the output, which is the sum of inputs, is $75 \%$ in conventional OEE measurement methods.

\section{OEE Measurement Focusing on Changeover Time}

Because of the above values as inputs and weight variables, the resulting OEE was obtained as 75.2 percent, as can be seen from the graph. Remember that the output, which is the sum of inputs, is $75 \%$ in conventional OEE measurement methods.

Table 3. Changeover Time for Die Attachment with improvement

\begin{tabular}{|c|c|c|}
\hline \multicolumn{3}{|c|}{ Die attachment } \\
\hline Operation description & Time (s) & Time (s) \\
after imp. \\
\hline
\end{tabular}




\begin{tabular}{|l|c|c|}
\hline Put the front spacers in the die & 60 & 0 \\
\hline Walk back the machine & 20 & 20 \\
\hline Put the rear spacers in the die & 50 & 40 \\
\hline Loosen the front die & 85 & 40 \\
\hline Loosen the rear die & 80 & 30 \\
\hline Lock the rear table & 60 & 40 \\
\hline Lock the front upper die & 230 & 40 \\
\hline Lock the rear upper die & 500 & 210 \\
\hline
\end{tabular}

Table 4. Changeover Time for Scrap material in the machine with improvement

\begin{tabular}{|c|c|c|}
\hline \multicolumn{3}{|c|}{ Scrap material in the machine } \\
\hline Operation description & $\begin{array}{c}\text { Time (s) } \\
\text { actual }\end{array}$ & $\begin{array}{l}\text { Time (s) } \\
\text { after imp. }\end{array}$ \\
\hline Loosen the ramp & 60 & 20 \\
\hline Walk to the ramp storage & 15 & 0 \\
\hline Walk back the machine & 30 & 0 \\
\hline Clear the ramp & 35 & 20 \\
\hline Walk to the ramp storage & 15 & 0 \\
\hline Walk back the machine & 10 & 0 \\
\hline Clear the ramp & 20 & 20 \\
\hline Walk to the ramp storage & 10 & 0 \\
\hline Walk back the machine & 10 & 0 \\
\hline Clear the ramp & 25 & 20 \\
\hline Walk to the ramp storage & 20 & 0 \\
\hline Walk back the machine & 10 & 0 \\
\hline Measure for which ramp to take & 20 & 0 \\
\hline Choose a ramp & 55 & 0 \\
\hline Walk to the machine & 10 & 0 \\
\hline Install the ramp & 35 & 0 \\
\hline Walk to take a ramp & 10 & 0 \\
\hline Choose a ramp & 55 & 0 \\
\hline Walk to the machine & 15 & 0 \\
\hline Install the ramp & 75 & 0 \\
\hline Measure for which ramp to take & 30 & 0 \\
\hline Walk to take a ramp & 10 & 0 \\
\hline Choose a ramp & 15 & 0 \\
\hline Walk to the machine & 10 & 0 \\
\hline TOTAL & 600 & 80 \\
\hline
\end{tabular}

Table 5. Changeover Time for Transport with improvement 


\begin{tabular}{|c|c|c|}
\hline \multicolumn{3}{|l|}{ Transport } \\
\hline Operation description & $\begin{array}{c}\text { Time (s) } \\
\text { actual }\end{array}$ & $\begin{array}{l}\text { Time (s) } \\
\text { after imp. }\end{array}$ \\
\hline Toe empty trailer to the machine & 120 & 0 \\
\hline Fit the trailer on the machine & 130 & 130 \\
\hline Unfit the trailer & 105 & 105 \\
\hline Toe the loaded trailer to the storage & 155 & 0 \\
\hline Toe the next die to the machine & 210 & 0 \\
\hline Fit the trailer on the machine & 190 & 130 \\
\hline Unfit the trailer & 150 & 105 \\
\hline Toe the empty trailer & 120 & 0 \\
\hline TOTAL & 1180 & 470 \\
\hline
\end{tabular}

Table 6. Changeover Time for Raw Material Handling with improvement

\begin{tabular}{|l|c|c|}
\hline \multicolumn{2}{|c|}{ Raw Material Handling } & Time (s) \\
\hline Operation description & 15 & 15 \\
& after imp. \\
\hline Walk to raw coil & 60 & 0 \\
\hline Prepare the coil & 60 & 0 \\
\hline Load the coil on the cart & 60 & 30 \\
\hline Load the coil on the axle & 45 & 20 \\
\hline Fit the coil stoppers & 20 & 10 \\
\hline Setup the plate & 10 & 0 \\
\hline Cut the straps & 35 & 95 \\
\hline Scrap the straps & 305 & 20 \\
\hline
\end{tabular}

From the tables above, the company still have room for improvement on the changeover time.

\section{Scenario\#1}

In a manufacturing plant, two pneumatic presses (scenarios) are presumed and their OEE is determined by concentrating on the exchange rate. According to the premises, measurement sources are considered:

- Changeover time are reduced to $50 \%$ from actual value.

- $\quad$ Total percentage of scrap are assumed to be maintained at $12 \%$.

The following table indicates the weight influence for each variable, the importance of each result for these situations, and the OEE for each scenario collected. 
Table 7. Production data with reduced changeover time 50\%

\begin{tabular}{|c|c|c|c|c|c|c|}
\hline \multicolumn{7}{|c|}{ Production data } \\
\hline $\begin{array}{l}\text { Shift } \\
\text { length }\end{array}$ & 672 & Hours & $\begin{array}{c}= \\
40320\end{array}$ & Min & & \\
\hline $\begin{array}{l}\text { Short } \\
\text { Breaks }\end{array}$ & 74 & Breaks of & 18 & Min each & 1332 & Min total \\
\hline $\begin{array}{l}\text { Meal } \\
\text { Break }\end{array}$ & 74 & Breaks of & 24 & Min each & 1776 & Min total \\
\hline $\begin{array}{l}\text { Down } \\
\text { time }\end{array}$ & 720 & Min & & & & \\
\hline $\begin{array}{l}\text { Ideal run } \\
\text { rate }\end{array}$ & 3.4198 & PPM & & & & \\
\hline $\begin{array}{l}\text { Total } \\
\text { pieces }\end{array}$ & 122299 & Pieces & & & & \\
\hline $\begin{array}{l}\text { Scrap } \\
\text { pieces }\end{array}$ & 14676 & Pieces & & & & \\
\hline
\end{tabular}

Table 8. OEE calculation with reduced changeover time 50\%

\begin{tabular}{|l|l|c|}
\hline Support variable & Calculation & Results \\
\hline Planned production time & Shift length - breaks & 37212 \\
\hline Operating Time & PPT - Downtime & 36492 \\
\hline Good pieces & Total pieces - scrap pieces & 107623 \\
\hline OEE Factor & Calculation & AQ OEE\% \\
\hline Availability (A) & Operating Time / PPT & $98.0 \%$ \\
\hline Performance (P) & (total pieces/Operating Time) / Ideal run rate & $88.0 \%$ \\
\hline Quality (Q) & Good pieces/Total pieces & $88.0 \%$ \\
\hline Overall OEE & A x P x Q & $75.9 \%$ \\
\hline OEE Factor & World Class & AQ OEE\% \\
\hline Availability & $80 \%$ & $98 \%$ \\
\hline Performance & $95 \%$ & $88 \%$ \\
\hline
\end{tabular}




\begin{tabular}{|l|c|c|}
\hline Quality & $99.9 \%$ & $88 \%$ \\
\hline Overall OEE & $85 \%$ & $75.9 \%$ \\
\hline
\end{tabular}

\section{Scenario\#2}

In a manufacturing plant, two pneumatic presses (scenarios) are presumed and their OEE is calculated by concentrating on the exchange rate. According to the premises, measurement sources are considered:

- Changeover time are reduced to $75 \%$ from actual value.

- Total percentage of scrap are assume to be maintained at $12 \%$.

The subsequent table specifies the weight factor for each variable, the importance of each result for these situations, as well as the OEE for each example collected.

Table 9. Production data with reduced changeover time $75 \%$

\begin{tabular}{|c|c|c|c|c|c|c|}
\hline \multicolumn{7}{|c|}{ Production data } \\
\hline $\begin{array}{l}\text { Shift } \\
\text { length }\end{array}$ & 672 & Hours & $\begin{array}{c}= \\
40320\end{array}$ & Min & & \\
\hline $\begin{array}{l}\text { Short } \\
\text { Breaks }\end{array}$ & 74 & Breaks of & 18 & $\begin{array}{l}\text { Min } \\
\text { each }\end{array}$ & 1332 & $\begin{array}{l}\text { Min } \\
\text { total }\end{array}$ \\
\hline $\begin{array}{l}\text { Meal } \\
\text { Break }\end{array}$ & 74 & Breaks of & 24 & $\begin{array}{l}\text { Min } \\
\text { each }\end{array}$ & 1776 & $\begin{array}{l}\text { Min } \\
\text { total }\end{array}$ \\
\hline $\begin{array}{l}\text { Down } \\
\text { time }\end{array}$ & 720 & Min & & & & \\
\hline $\begin{array}{l}\text { Ideal run } \\
\text { rate }\end{array}$ & 3.4198 & PPM & & & & \\
\hline $\begin{array}{l}\text { Total } \\
\text { pieces }\end{array}$ & 122299 & Pieces & & & & \\
\hline $\begin{array}{l}\text { Scrap } \\
\text { pieces }\end{array}$ & 14676 & Pieces & & & & \\
\hline
\end{tabular}


Table 10. OEE calculation with reduced changeover time $75 \%$

\begin{tabular}{|c|c|c|}
\hline Support variable & Calculation & Results \\
\hline Planned production time & Shift length - breaks & 37212 \\
\hline Operating Time & PPT - Downtime & 36492 \\
\hline Good pieces & Total pieces - scrap pieces & 107623 \\
\hline OEE Factor & Calculation & AQ OEE\% \\
\hline Availability (A) & Operating Time / PPT & $98.0 \%$ \\
\hline Performance $(\mathrm{P})$ & (total pieces/Operating Time) / Ideal run rate & $88.0 \%$ \\
\hline Quality (Q) & Good pieces/Total pieces & $88.0 \%$ \\
\hline Overall OEE & $A \times P \times Q$ & $75.9 \%$ \\
\hline OEE Factor & World Class & AQ OEE\% \\
\hline Availability & $80 \%$ & $98 \%$ \\
\hline Performance & $95 \%$ & $88 \%$ \\
\hline Quality & $99.9 \%$ & $88 \%$ \\
\hline Overall OEE & $85 \%$ & $75.9 \%$ \\
\hline
\end{tabular}

Several scenarios have been expected for each Intelligent System in this segment, minimizing the changeover period to calculate the OEE and achieving the investigational results. It is necessary to reference that the suggested technique, irrespective of its substance and sophistication, can be applied in any production process. Depending on the manufacturing process, other inputs may also be taken into account.

\section{DISCUSSION}

The observations from chapter five will be explored extensively here in this chapter. Discussions were held on the following subchapters to address the research questions mentioned for this report.

\section{Availability Issues}

The idea of availability is linked to downtime; downtime can be reduced by concentrating on planned downtime. It is recognized. Strengthening the rest period can give the machine operator an adequate rest in ideal condition for continuous work. In the case of insufficient rest, issues such as unexplained interruption time, pause, or prolonged change and installation can occur. Unforeseen delays may be due to many reasons from serious to minor cases.

The machine operator caught an accident is one of the grave scenarios. When this happens, the machine is stopped. It is defined as an unplanned shut downtime that the time it took to get the machine operational again. Several causes can contribute to such an event; it may be personal or even management. What may trigger the disruption due to the tiredness or tension of the operator. In this case, part of the planned down time must be carefully planned because it is necessary to determine the unplanned downtime.

Although it is not possible to control the frequency of unplanned downtime, it can be minimized by introducing certain preventive measures. Certain serious cases may include electrical supply shortages, shortages of raw materials, computer 
malfunctions or any instances that have taken a long time to recover for service. Preventive maintenance tasks allotted in scheduled downtime are responsible for making some repairs to avoid such scenario occurring as much as practicable in the case of system failure.

Small cases are characterized by the short time the procedure was taken off. These can be an emergency shower, a brief delay to pick up emergency calls or some additional incident that triggers small interruptions. It may also be reasons of avoidance, such as taking a brief break for smoke at practice. Often small stoppages are triggered as supervisors are removed to give the operator any talks or follow-up. It is necessary to determine carefully whether this kind of stoppage is unplanned or planned. The briefing provided through morning or at any particular planned time would be a planned break. Furthermore, if an unexpected meeting or conversation is conducted during work time, slight delays will be calculated according to the period of the task.

The user is also trained mentally and physically prepared for a system shift and set-up by an appropriate rest time. In the manual or handbook, the period needed for system shift and set-up is specified. Nevertheless, it is often affected in the real world by all kinds of explanation that induces the expansion. One of these is undoubtedly the operator's mental and physical ability to conduct the transition and set-up at the maximum level. Thus, offering a seamless system changeover and set-up is a focus on daily maintenance. When computers are not operated on a regular basis, time may be spent during a system changeover for the difficulties of set-up. During a complicated system changeover or set-up, time can also be spent to find the source of the problematic.

\section{Performance Issues}

It is because of system fatigue, poor content and inefficiency that performance problems for all three computers are caused. The wear of the computer is one reason for constantly triggering problems with output. The system can degrade with time as a result of regular use or intense operation. A computer is fully worn out and up to a certain time a new replacement is necessary. Before it's fully worn out, the still in use for production computer would definitely hinder manufacturing speed and cause output loss. Worn computer usually causes small output stoppages or is manufactured at a slower pace. Based on the system and equipment wear frequency, certain devices simply require constant servicing, such as lubricating or washing, to prevent the computer from being worn out while others may involve changing components or even the whole machine.

The substandard content is another factor that causes performance problems. The raw materials imported from outside suppliers often included damaged content. The faulty content causes problems such as computer clogging, resulting in a return loss of performance. Minor speed reduction often occurs when the user has to remove and replace the defective substance manually. The operator shall recover new raw materials from stores or warehouses or the subsequent machine beforehand, and there will be a longer loss of speed.

Last but not least, operators ' inefficiency is also a major cause of loss of performance. There are many reasons why an operator might not function. Tiredness, stress at work, lack of training, lack of oversight or inspiration may arise. It is necessary for the operator to function in optimal condition to will the performance loss.

\section{Quality Issues}

Subsequently the firm is a UK-based company, there are no major quality problems with most of their equipment. A set of strict policies minimizes the defective yield. Nonetheless, the consistency rating should be increased to 100 percent as close as possible. A slight reduction in the quality rate suggests a slight upsurge in the production of defective units. Such defects increase rework expenses such as extra electricity and inventory processing charges. Therefore, the organization is advised to maintain the current production yield level or improve if it improves.

\section{The advantages of OEE optimisation}

The OEE's ease of measurement makes it a key user-friendly performance metric. In order to calculate the losses of critical parts in production processes, OEE provides a basic quantitative measure, namely access, output rate and price rate. OEE can also identify and implement immediate changes via the clear information derived from loss calculation, thus identifying complicated production problems. Not all of this can be done by an OEE. OEE can also be used for improving or repairing performance. Using the OEE metric as a key performance indicator, the operator or supervisor can also provide the upper management with the correct feedback. In exchange, this helps upper management to make more informed feedback-based decisions. In fact, the OEE measure can also be seamlessly integrated into its applications for process management and regulation. This machine helps technicians or managers to quickly control all assembly line instruments and parts. 
OEE is used frequently to support the cost reduction of plant owners. The costs reductions resulting from the OEE are particularly interesting during these recessional times. OEE has been around for a long time, at least since the sixties. Nonetheless, recent developments in real-time OEE as a cost-saving tool have been given more attention.

\section{Suggestions to the company}

Some proposals have come to mind for the business after the conversation on the concerns of the three components in the figure of the OEE. Since client computers are not experiencing any significant quality issue, there will be no recommendation on functionality for development.

It is confirmed that the machine has an 88.0 percent low performance score. Therefore, company will be offered three recommendations for implementation to curb the issue.

1) Replace a new machine

When new machine never has the question of slowing down or halting, it will leave for human error only the remaining deducted amount.

2) Make more regular inspection and maintenance

Company was suggested for the detailed routine checking of machine and for maintenance of all parts necessary to increase the efficiency of the machine.

3) Add third working shift

The small performance rate in a production system allows computer B to be a bottleneck. The recommendation to counter this problem is to incorporate buffer units in another change at midnight. As derived from data analysis in result, the system is recognized as having a quality problem where it only achieves an output rating of 88.0 percent relative to the quality score of the world class OEE, 99 percent. The fourth is a guideline for raising the price performance.

4) Effective data collection

This recommendation recommends the collection of data on an hourly or a shorter time basis to allow the collection of the data in real time. Why is it also suggested to analysis where the most common errors can be effectively underscored and the root causes examined.

\section{CONCLUSION}

Methods of Intelligent Systems (IS) can be used to improve precision and to reduce the limited OEE calculation. These IS approaches, in particular the Fuzzy Inference Systems, offer new techniques for business OEE estimates. In the OEE estimation, some of the advantages of using FIS are the cope with uncertainty and confusion, the value of user awareness and the ability to add additional information to the system. These can be seen through the result of study achieving an OEE score comparable the standard calculation of OEE. An OEE calculation in real time provides simple daily knowledge on the performance standard of a machine. To order to generate accurate and factual information, the company needs to be provided with real-time data because real-time data accelerates corrected behaviour. Comprehensive OEE knowledge also gives customers constant line tracking and advice to avoid disruption, poor product quality and loss of revenue in due course. When a production line is marked as a strong OEE, this is a good indicator for high production activities, but a long-term rating needs constant refining.

\section{REFERENCES}

Brandon-Jones, A. (2014). Wiley Encyclopaedia of Management, Invited entries:: Zone of tolerance; Service recovery; service quality; failure analysis; Importance-performance matrix; Failure in operations; Queuing analysis; Decoupling; Overall equipment effectiveness. In Wiley Encyclopaedia of Management 3rd Edition.: McGrawHill.

Carboni, A., Ragaini, E., \& Ferrero, A. (2017). A fuzzy inference system for power systems. Paper presented at the 2017 IEEE 3rd International Forum on Research and Technologies for Society and Industry (RTSI).

Irhirane, E., Bounit, A., \& Dakkak, B. (2017). Estimate of OEE (Overall Equipment Effectiveness) Objective from Classical OEE. International Journal of Performability Engineering, 13(2), 135-142.

Ismail, M., Nurdin, M., \& Purba, H. H. (2018). Improving Quality and Work Quality at the 2019 World Skills Competition in Industrial Control. SSRG International Journal of Industrial Engineering (SSRG-IJIE), 5(3).

Pourjavad, E., \& Mayorga, R. V. (2019). A comparative study and measuring performance of manufacturing systems with Mamdani fuzzy inference system. Journal of Intelligent Manufacturing, 30(3), 1085-1097. 
Rahman, C. M., Hoque, M., \& Uddin, S. M. (2014). Assessment of total productive maintenance implementation through downtime and mean downtime analysis (case study: a semi-automated manufacturing company of Bangladesh). Assessment, 4(09).

Saha, D., Syamsunder, M., \& Chakraborty, S. (2016). SAP OEE: A New Product for Manufacturing Performance Management. In Manufacturing Performance Management using SAP OEE (pp. 11-22): Springer.

Shirose, K. (1992). TPM for workshop leaders: Productivity Press.

Singh, R., Shah, D. B., Gohil, A. M., \& Shah, M. H. (2013). Overall Equipment Effectiveness (OEE) calculationAutomation through hardware \& software development. Procedia Engineering, 51, 579-584.

Tabikh, M. (2014). Downtime cost and Reduction analysis: Survey results. In. 